\title{
A VIAGEM DE JUST-JEAN-ÉTIENNE ROY (ARMAND DE B***) AO OESTE DO RIO GRANDE DO SUL. 1 - VISITA A AIMÉ BONPLAND NA VILA DE SÃO BORJA ${ }^{1}$
}

\author{
DANIEL LENA MARCHIORI NETO² JOSÉ NEWTON CARDOSO MARCHIORI ${ }^{3}$
}

\section{RESUMO}

Os capítulos do livro de viagem de Jean-Just-Étienne Roy (Armand de B***), relativos à visita a Aimé Bonpland na vila de São Borja, oeste do Rio Grande do Sul, são presentemente publicados pela primeira vez em português.

Palavras-chave: Aimé Bonpland, Armand de B***, Itaqui, Just-Jean-Étienne Roy, literatura de viagem, Rio Grande do Sul, São Borja.

\section{ABSTRACT}

[The travel of Just-Jean-Étienne Roy (Armand de B***) to the west of Rio Grande do Sul State (Brazil). 1 - The visit to Aimé Bonpland in the village of San Borja].

The chapters of the travel book of Just-Jean-Étienne Roy (Armand de B***) concerning to his visit to Aimé Bonpland in the village of San Borja, west of Rio Grande do Sul State (Brazil) are presently published in Portuguese, for the first time.

Keywords: Aimé Bonpland, Armand de B***, Brazil, Just-Jean-Étienne Roy, Municipality of Itaqui, Municipality of San Borja, Rio Grande do Sul State, Travel Literature.

\section{INTRODUÇÃO}

Publicado originalmente em francês, no ano de 1860, a obra "Mes voyages avec le Docteur Philips dans les Républiques de La Plata (Buenos-Ayres, Montevideo, La Banda-Oriental etc.)" teve várias edições em sua pátria de origem $^{4}$, devido, sobretudo, ao grande interesse que o nome do botânico Aimé Bonpland ${ }^{5}$ suscitava na Europa, desde que viera definitivamente para a América do Sul em 1816.

Ninguém desconhecia nos meios político e cultural que esse antigo companheiro de Alexander von Humboldt ${ }^{6}$ na célebre viagem ${ }^{7}$

1 Recebido em 12-3-2014 e aceito para publicação em 05-5-2014.

2 Professor, Dr. Universidade Católica de Pelotas. danielmarchiorineto@gmail.com

3 Professor, Dr. Universidade Federal de Santa Maria. Bolsista de Produtividade em Pesquisa (CNPq-Brasil). marchiori@pq.cnpq.br

4 Além da edição de 1860, Abeillard Barreto também examinou as de 1863 e 1884; a presente tradução baseia-se na de 1876 . A obra mereceu, portanto, pelo menos quatro edições em francês.

5 Aimé Jacques Alexandre Goujaud Bonpland (17731858), médico e viajante-naturalista francês, um dos às "Regiões Equinociais do Novo Continente", e ex-intendente do Palácio de Malmaison ${ }^{8}$, fora mantido prisioneiro por cerca de dez anos no Paraguai, a mando do ditador Francia ${ }^{9}$, e que após a libertação escolhera viver às margens do rio Uruguai, na brasileira São Borja, uma vila

maiores botânicos da primeira metade do século dezenove.

6 Friedrich Wilhelm Karl Heinrich Alexander von Humboldt (1769-1859), naturalista e viajante alemão. Fundador da moderna Geografia Física e "Descobridor Científico do Hemisfério Ocidental", Humboldt foi uma das mais destacadas personalidades mundiais de sua época. De sua vasta bibliografia destaca-se, justamente, "Le voyage aux régions equinoxiales du Nouveau Continent, fait em 1799-1804”, escrita em parceria com Aimé Bonpland.

7 Realizada de 1799 a 1804 , essa viagem foi a primeira expedição científica de grande repercussão sobre a América do Sul, pelo valioso aporte que trouxe ao conhecimento da natureza regional.

8 Casa de campo (ou castelo) da Imperatriz Joséphine de Beauharnais, esposa de Napoleão Bonaparte, situada no departamento francês de Hauts-de-Seine, em meio a um parque de mais de 700 hectares.

9 José Gaspar Rodríguez de Francia (1776-1840). Doutor em Teologia (Universidad de Córdoba, Argentina), revolucionário e político paraguaio, nomeado "Ditador 


\section{MES VOYAGES}

AVEG LE DOGTEUR PHILIPS

DANS LES RÉPUBLIQURS

DE

\section{LA PLATA}

(BUENOS-AYRES, MONTEVIDEO LA BANDA-ORIENTAL ETC.)

PAR ARMAND DE $B^{* * *}$

Brossand

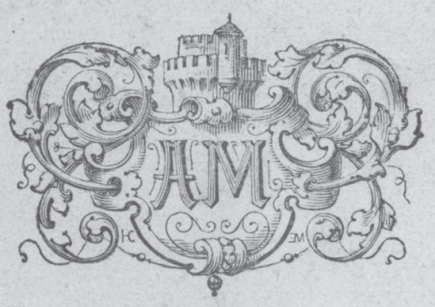

\section{TOURS}

\section{ALFRED MAME ET FILS, ÉDITEURS}

M DCGG LXXVI

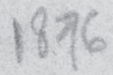

FIGURA 1 - Folha de rosto da edição francesa de 1876 da obra parcialmente traduzida. O autor, Just-Jean-Étienne Roy, assina com o pseudônimo "Armand de B***”. O nome "Brossard", escrito a mão, é uma tentativa equivocada da identificação do autor. 
esquecida nos confins do império e, mais tarde, em sua estância de Santa Ana, na província argentina de Corrientes. Mesmo distante, a vida romanesca do grande cientista era acompanhada com um misto de incredulidade e interesse, sobretudo pela dedicação do velho amigo Humboldt, que nunca deixou de prestigiá-lo, e por relatos de viajantes que eventualmente o encontraram nas capitais do Prata ou o foram visitar em distantes rincões do continente.

O tema Bonpland foi o objetivo principal da viagem de Just-Jean-Étienne Roy de acordo com Abeillard Barreto ${ }^{10}$, o maior conhecedor da bibliografia sul-rio-grandense. A respeito do texto traduzido, três aspectos chamam especial atenção: a utilização de um pseudônimo (Armand de $\mathrm{B}^{* * *}$ ) por parte do autor, em contraste com outras obras de sua autoria; as escassas referências pessoais a Aimé Bonpland, objetivo principal da obra; e a inconsistência das descrições de lugares visitados, inclusive de São Borja. Estes três fatos, reunidos, bastam para colocar sob suspeita a efetiva realização da viagem. A esse respeito, Stephen Bell, autor da mais recente e completa biografia sobre a longa vivência do cientista francês na América, também manifestou estranheza pela escassa informação fornecida pelo francês, mas sem contestar a autenticidade do relato:

One French travel account, the work of the pseudonymous Armand de B. (Just-JeanÉtienne Roy), traveling with a Dr. Philips, was structured entirely around a visit made in the 1840s from the mouth of the Plata ascending the Uruguay River to Bonpland's home at São Borja. They planned to use Bonpland's knowledge of the region as the basis for attempting a journey into Paraguay, one that

Perpétuo da República do Paraguai” a partir de 1816. Outro cognome associado ao ditador é o de "El Supremo", título dado à obra biográfica escrita pelo eminente intelectual e historiador paraguaio Augusto Roa Bastos (1917-2005).

${ }^{10}$ BARRETO, A. Bibliografia sul-riograndense. Rio de Janeiro: Conselho Federal de Cultura, 1976. v. 2. p. 1.165 . does not seem to have taken place. Roy found little of originality to report in his book. He didn't comment on Bonpland's vast garden planted with oranges and European trees. His material circumstances were described as highly modest, in that the only items of note were portraits of Napoleon and Joséphine in a small reception room. ${ }^{11}$

Por demandar análise mais acurada, o tema da autenticidade da viagem à América do Sul merece abordagem em artigo a parte. Mesmo assim, pode-se adiantar que Just-Jean-Étiénne Roy é autor de vasta bibliografia ainda não traduzida ao português, principalmente sobre temas históricos ${ }^{12}$, de divulgação geográfica ${ }^{13}$, e de relatos de viagem ${ }^{14}$.

Apesar de sua reconhecida fragilidade informativa, não é difícil entender o sucesso que a obra alcançou na segunda metade do século dezenove, como demonstrado por suas várias reedições: além da curiosidade por lugares exóticos, aspecto marcante ao longo do século dezenove e início do século vinte, decorrente da limitação oferecida pelos meios de transporte então disponíveis, e da inexistência do "turismo" como prática usual, o livro em foco in-

${ }^{11}$ BELL, S. A life in Shadow. Aimé Bonpland in Southern South America, 1817-1858. Stanford, California: Stanford University Press, 2010. p. 158.

${ }^{12}$ Entre outros: Élisa Schumier: ou la juive convertie; Histoire de Marie-Antoinette; Histoire de la Chevalerie; Histoire abrégée des Missions catholiques dans les diverses parties du monde depuis la fin de Xve siècle jusqu'a nos jours; Mozart ou la jeunesse d'un grand artiste; Le secret de Madeleine; Histoire de Turenne; e Histoire de Fénelon.

${ }^{13}$ Entre outros: La Russie moderne: son origine, ses moeurs, son histoire, jusqu'à nos jours; La Chine et la Cochinchine: aperçu sur la Chine, sa géographie physique et politique, son climat, sés productions et sa population suivi de l'Histoire; Souvenirs et récits d'un ancien missionaire a la Cochinchine et au Tong-King; e L'Australie: découverte, colonisation, civilization.

${ }^{14}$ Entre outros: Quinze ans de séjour à Java et dans les principales îles de l'archipel de la Sonde et des possessions néerlandaises des Indes Orientales: Souvenirs d'un ancien officier de la Garde Royale recueillis et publiées par J. F. E. Roy; e Excursion d'un touriste au Mexique pendent l'année 1854. 


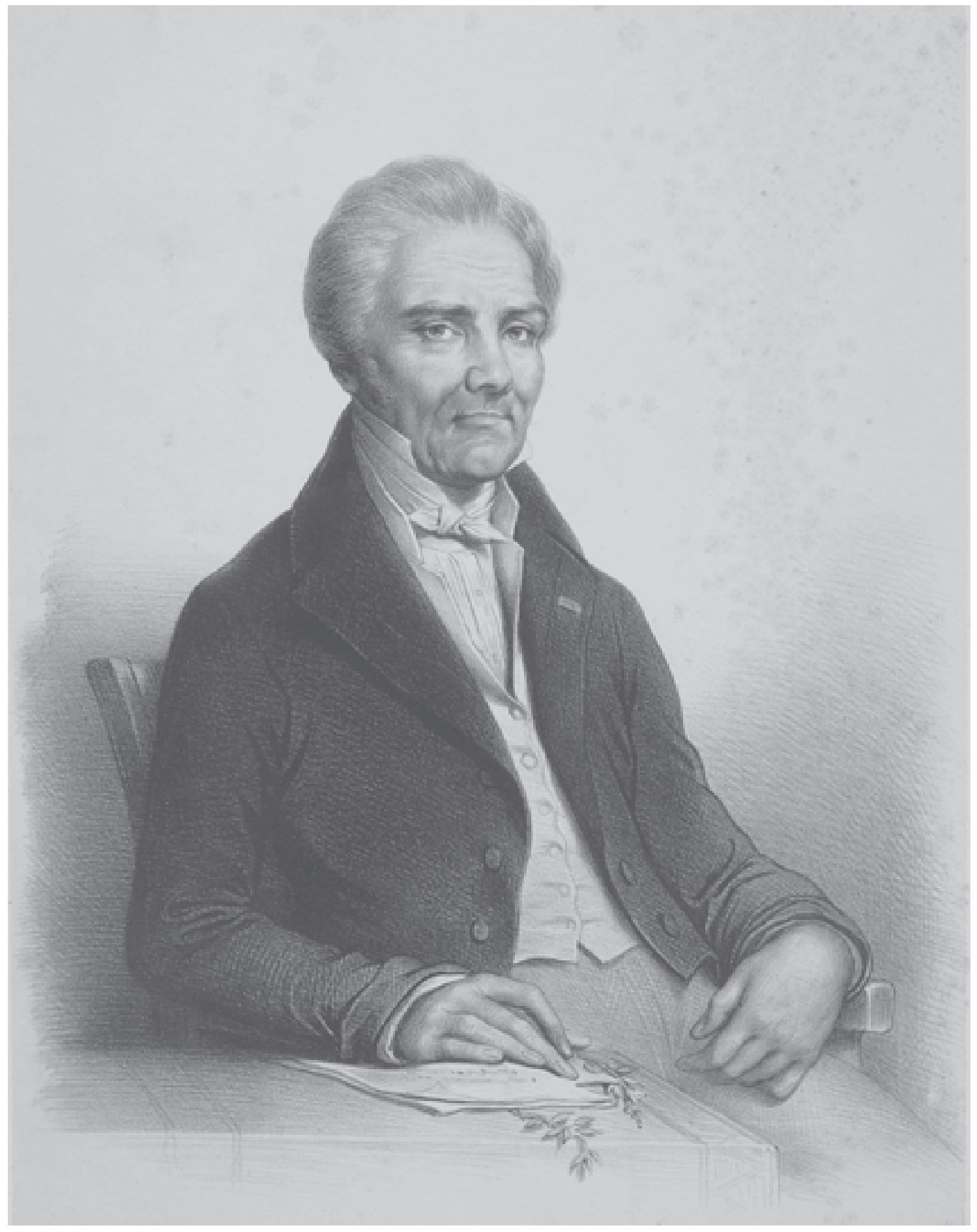

FIGURA 2 - Retrato de Aimé Bonpland em São Borja (cerca de 1845); obra de Alfred Demersay, litografado por Achile Devería. 
tegrou coletânea aprovada pelo Arcebispo de Tours, indicada para proveito de "jovens cristãs", público numeroso nos colégios da época ${ }^{15}$.

O texto traduzido compreende a parte final do capítulo 10 e quase todo o capítulo 11, com exceção dos comentários finais sobre os "motivos que forçaram" o autor a "deixar Buenos Aires" e uma análise sobre "estado atual da Argentina", temas que, embora interessantes, fogem, inteiramente, aos objetivos da presente publicação. Resta informar que o capítulo 9, embora dedicado quase que inteiramente à "História do Sr. Bonpland", não traz nenhuma novidade biográfica, motivo pelo qual também não justifica sua tradução.

\section{VIAGEM A SÃO BORJA E VISITA A BON- PLAND}

Então nós passamos ${ }^{16}$, sucessivamente, pelas aldeias arruinadas de Belén ${ }^{17}$ e Santa Rosa ou Bella Unión ${ }^{18}$. Nesta última não restava mais do que quarenta ranchos, sendo que havia mais de duzentos em 1832, o que então tornava a localidade mais povoada e comercial do que Salto $^{19}$, dispondo de aduana, de um comandante

15 "Bibliothèque de la Jeunesse Chrétienne, approuvée par $\mathrm{M}^{\mathrm{gr}}$ L'Archevèque de Tours", como indicado na falsa folha de rosto da edição consultada (1876). A título de informação, Mgr. é abreviatura de Monseigneur (Monsenhor).

${ }^{16}$ Em viagem de barco pelo rio Uruguai, o autor descreve as localidades de Paysandu e Salto, antes de chegar a Bella Unión. Por ser a última parada, antes de entrar na província do Rio Grande do Sul, o texto traduzido começa com a curta referência a Bella Unión, última localidade da República Oriental do Uruguai.

${ }^{17}$ Belon, no original. Trata-se de Belén, atual vila do Departamento de Salto, situada junto à foz do arroio Yacuy no rio Uruguai. A localidade foi reconhecida como "pueblo" somente em 12 de janeiro de 1860.

${ }^{18}$ Bella-Union, no original. Santa Rosa é o nome antigo de Bela União (Bella Unión, em espanhol), atual cidade do departamento de Artigas, situada frente à Monte Caseros (Corrientes, Argentina) e a curta distância da cidade gaúcha de Barra do Quaraí.

${ }^{19}$ Fundada por Fructuoso Rivera em 13 de maio de 1829, com o objetivo de assentar índios guaranis trazidos das Missões, a localidade desempenhou papel proeminente do porto, e de um comandante militar encarregado da polícia. Foi o último povoado da Banda Oriental em direção às Missões Brasileiras, cuja fronteira fica a apenas oito quilômetros de distância. Este lugar dista $160 \mathrm{~km}$ de Salto, pelo rio.

Não tardamos a chegar a terras brasileiras (província do Rio Grande do Sul ou de São Pedro), e percebemos, com satisfação, uma diferença notável no aspecto do país: campos verdes, árvores no campo, muitos rebanhos nas encostas de coxilhas ou nas planícies; veados e avestruzes em abundância, enfim, um aspecto de vida e de cultura que contrastava nitidamente com os desertos que acabáramos de percorrer. Os brasileiros não são mais diligentes ou trabalhadores do que seus vizinhos orientais e argentinos; mas as estâncias se multiplicaram muito nesses países, durante e depois da guer$\mathrm{ra}^{20}$. Por vezes também se preocupam de queimar os campos, prática que renova a grama e contribui significativamente para a fertilidade, devido aos sais contidos nas cinzas ${ }^{21}$, além de destruir pragas, como répteis, gafanhotos e formigas, que pululam por todos os lugares durante o calor.

Nós acampamos pela primeira vez em terra brasileira à margem da mata ciliar do arroyo del Tigre ${ }^{22}$. Juntaram-se a nós quatro brasileiros armados que vieram em uma longa canoa feita de um único tronco de árvore. Eles nos deram, de boa vontade, um pedaço de carne fresca, produto de que nós muito precisávamos, uma vez que o nosso charque, embalado em couro antes de ser seco, começou a estragar devido às chuvas incessantes e, salvo alguns pombos, que-

no início da história do Uruguai. Cabe salientar, todavia, que boa parte dos índios abandonou o povoado poucos anos após sua fundação, retornando à província do Rio Grande do Sul, fato que explica a decadência referida no texto.

${ }^{20}$ Referência ao decênio da farroupilha (1835-1845).

${ }^{21}$ Sabe-se, hoje, que esta prática é altamente prejudicial a longo prazo.

${ }^{22}$ Em espanhol, no texto; daqui por diante, as palavras escritas originalmente nessa língua aparecem em itálico. 
ro-queros ${ }^{23}$ (teruteros) e veados, quando se podia pegar, comíamos a carne ruim, como regra, muito salgada, torrada ou moída, com farinha de mandioca em lugar de pão. Eles se apressaram a dizer que não tínhamos nada a temer em terra brasileira, nem de animais, nem de homens, mas que não era assim no país de onde tínhamos vindo. Contaram-nos vários atos de banditismo que tinham acontecido recentemente, e afirmaram que nós tivemos muita sorte por não termos sido atacados por índios ou gaúchos errantes que rondam as bordas do Uruguai para saquear viajantes. Não era mais preciso se preocupar com nada disso, e o que os brasileiros nos repassaram, como recentes, eram, quem sabe, acontecimentos de outro tempo ou, como de costume, apenas calúnias sobre os seus vizinhos.

No mesmo dia, passamos pelo povoado de Santa $\mathrm{Anna}^{24}$, a primeira guarda brasileira ao se remontar o rio Uruguai. Quatro dias mais tarde, ao admirar um belo nascer do sol, o nosso chefe nos disse, mostrando-nos ao longe uma palmeira muito alta: chegou o fim de seus problemas; aqui é a estância de São Marcos ${ }^{25}$, distante apenas quarenta quilômetros da vila de Itaqui.

${ }^{23}$ Vanneaux armés, no original francês: Vanellus chilensis (Molina, 1752), ave da família Charadriidae.

${ }^{24} \mathrm{O}$ autor refere-se, certamente, a Santana Velha, localidade situada uns $30 \mathrm{~km}$ ao sul da atual cidade de Uruguaiana. Composta de alguns ranchos de moradores, a extinta localidade dispunha de um posto fiscal e acampamento militar. Em 1840, esse povoado foi destruído por uma grande enchente, levando o governo farrapo, em 24 de fevereiro de 1843, a reconstruir o povoado no atual sítio urbano em que se encontra Uruguaiana. A localidade de Santa Ana referida pelo autor, em outras palavras, é a precursora da moderna Uruguaiana, que mantém, em seu próprio nome, essa vinculação histórica: Santana do Uruguai - Uruguaiana. Se o autor não menciona Uruguaiana, é provável que a viagem tenha acontecido antes de fevereiro de 1843. Cabe notar, ainda, que o autor também não cita Paso de los Libres, cidade argentina situada frente à Uruguaiana e que foi fundada pelo General Joaquin Madariaga em 12 de setembro de 1843 .

25 Atual vila e sede de distrito do município de Uruguaiana, situada próximo à foz do rio Ibicuí.
- E de São Borja, eu perguntei.

- Cem quilômetros além de Itaqui. Resignei-me a murmurar. À noite, dormimos na estância de São Marcos. O estancieiro brasileiro recebeu-nos muito bem e nos deu uma excelente refeição, regada com um bom vinho do Porto.

Depois de dois dias de descanso em São Marcos, uma boa brisa de sudeste empurrou suavemente; passamos a confluência do IbicuíGuazu $^{26}$, antigo limite norte da Banda Oriental $^{27}$, a quarenta quilômetros ao sul de Itaqui ${ }^{28}$. Chegamos à noite à aldeia tão pomposamente anunciada. Não era mais do que uma má cidade, composta de uns trinta ranchos mal construídos e dispostos sem qualquer ordem. Esta aldeia é a segunda guarda brasileira que se passa, vindo de Salto. Há um comandante militar subordinado ao de São Borja, um juiz de paz, etc.

Ficamos dois dias em Itaqui, porque tivemos que mudar de barco. Nós ganhamos na mudança, porque a nossa nova chalana era coberta de um teto leve, feito de juncos e couros, presos por correias. Portanto, não havia mais necessidade de repousar em terra todas as noites e, durante o intervalo que ainda nos separava de nosso destino, pudemos desfrutar, à vontade, o esplêndido espetáculo do rio Uruguai, vestido em ambas as margens de belas florestas, onde o luxo de vegetação brasileira se mostra a cada passo.

Finalmente, quatro dias após nossa partida de Itaqui chegamos ao porto de São Borja. O

${ }^{26}$ Rio Ibicuí, simplesmente, na atualidade.

${ }^{27} \mathrm{O}$ autor refere-se ao limite entre as colônias pertencentes a Portugal e Espanha, determinado pelo Tratado de Madrid (1750), que definia como portuguesas as terras situadas à margem direita (ou ao norte) do rio Ibicuí, e como espanholas as da margem esquerda (ao sul do mesmo rio) .

${ }^{28}$ Mais antiga do que Uruguaiana, Itaqui teve o início do povoamento de sua sede em 1821 (FORTES, A.B.; WAGNER, J.B.S. História administrativa, judiciária e eclesiástica do Rio Grande do Sul. Porto Alegre: Editora Globo, 1963. p. 267). Em 6 de dezembro de 1858, quando Itaqui desmembrou-se do município de São Borja, a população da vila era de aproximadamente quatro mil habitantes. 
porto ou passo é, simplesmente, uma clareira bastante íngreme, aberta na mata, e bastante inconveniente para aqueles que têm bens para embarcar ou desembarcar.

São Borja (a vila ou cidade) situa-se a mais de quatro quilômetros do porto. Depois de havermos passado pela floresta da margem esquerda por caminhos tortuosos e lamacentos, encontramos os ranchos do porto. Nós carregamos nossa bagagem e, sem perder tempo, nos dirigimos à cidade, apesar do calor excessivo. Os habitantes se surpreendiam muito, pois não estavam acostumados, como os argentinos e orientais, a dar um único passo a pé. Atravessamos primeiro um campo despojado de árvores e arbustos, mas coberto de uma grama fina e perfumada. Logo a torre quadrada da igreja se oferecia aos nossos olhos. Enquanto subíamos, encontramos, à nossa frente, bosques, pomares e chácaras ${ }^{29}$ cercadas por fossos cheios de bromélias de folhas vermelhas como sangue e belas flores em espigas. Ao longe, víamos bosques de pequena extensão, espaçados como as fazendas da Alta-Normandia ${ }^{30}$. Desviando-nos, percebemos que tínhamos amplo domínio sobre o rio Uruguai, cujo curso sinuoso era parcialmente encoberto por densas e belas florestas: é que a estrada se eleva com suave declive em direção a São Borja. ${ }^{31}$

Ao chegar a São Borja, nosso primeiro pensamento foi o de nos informar sobre a moradia do Sr. Bonpland. Uma mulher índia que conhecemos, ou melhor, mestiça, indicou-nos clara-

29 "É a mesma coisa que chacras, em espanhol; mas aqui, assim como na província de Corrientes, esta palavra não é utilizada apenas para uma fazenda agrícola, referindose, também, a qualquer tipo de casa de campo, o que corresponde às quintas de Buenos Aires" (nota do autor). As palavras em itálico aparecem em espanhol, no texto original (nota do tradutor).

${ }^{30}$ A Alta Normandia (Haute Normandie), uma das 26 regiões administrativas da França, compreende dois departamentos: Seine-Maritime e Eure.

31 Aqui termina o Capítulo 10 e começa, na sequência, o texto do Capítulo 11. mente por gestos, que compreendemos mais facilmente do que pela língua, mistura de guarani com algumas palavras em espanhol e português, bastante incompreensível para nós.

Seguindo as indicações dessa mulher, nos dirigimos à extremidade norte da vila e, quando nos encontrávamos perto do campo, avistamos um vasto jardim, plantado com laranjeiras e arbustos de origem européia. Uma sebe de bromélias a separava das propriedades vizinhas e, no meio, havia um rancho do mais simples aspecto. "Deve ser aqui", disse o Sr. Philips e, sem hesitar, entrou em um tipo de alameda, fechada por um um portão com grades, que conduzia à casa. Eu o segui a alguns passos. Quando nos aproximamos, um empregado índio, que provavelmente nos viu chegando, apareceu à porta e perguntou-nos em espanhol, educadamente, o que queríamos.

- Não é esta a casa do Sr. Bonpland?, interrogou o Sr. Philips.

- Sim, señor.

- Ele se encontra em casa?

- Sim, señor.

- Neste caso, diga-lhe, por favor, que dois franceses querem vê-lo e prestar suas homenagens.

- Entrem, señores, respondeu o empregado, eu vou avisar meu mestre; e dizendo estas palavras, levou-nos a uma pequena sala de estar, mobiliada muito modestamente, cujos principais ornamentos eram dois retratos, um do imperador Napoleão I e o outro da imperatriz Josefina.

Nós ainda estávamos em pé, olhando essas pinturas, quando a porta da sala se abriu e vimos entrar o próprio Sr. Bonpland. Sem nunca o termos visto, nós o reconhecemos prontamente pelo retrato que tínhamos do Sr. Thedy ${ }^{32}$. Somente os cabelos brancos e as rugas de seu rosto faziam supor a idade, pois o frescor da abor-

\footnotetext{
${ }^{32}$ Cidadão suíço, "originário do cantão de Vaud", que, de acordo com palavras textuais, teve a "extrema bondade" de acolher o autor e o Sr. Philips por três dias em Salto, Uruguai, na viagem de ida a São Borja.
} 
dagem, a expressão dos olhos, e o som de sua voz cheia e vibrante, acusavam, no máximo, sessenta anos. "Senhores, disse ele, curvandose graciosamente, eu agradeço a todos que vêm me visitar, em minha solidão, mas quando são compatriotas, eles são duplamente bem-vindos".

O Sr. Philips o pôs informado, brevemente, de nossos projetos, e o fez saber da finalidade de nossa visita. O velho ouviu com grande interesse e benevolência, e disse ao meu companheiro de viagem, quando ele acabou de falar: "Um curto tempo nos será necessário para tudo isso, mas primeiro vocês precisam de descanso, refrescar-se, mandar vir os seus pertences e, quando estiverem instalados aqui da melhor maneira possível, vamos falar de negócios".

Ao mesmo tempo, ele nos levou para a sala de jantar, onde foram servidas carnes frias, frutas e vinho, enquanto enviou um de seus servos ao porto, para trazer nossa bagagem. À noite, finalmente, estávamos sentados em sua casa e, em poucas horas, nos tínhamos tornado velhos amigos, como de vinte anos.

Ficamos na casa do Sr. Bonpland quinze dias; foi um dos períodos mais agradáveis de minha vida e dele conservarei, para sempre, uma preciosa lembrança. Em pouco tempo se estabeleceu entre o Sr. Philips e ele uma conversa interessante, que eu escutava com silêncio religioso. Dotado de memória incomum, o exintendente ${ }^{33}$ de Josefina possuía conversa fácil, brincalhona, semeada de traços anedóticos e cativantes. Por vezes, a minha imaginação, entregando-se a idéias mitológicas, dava-me a impressão de jogar, de fato, o papel de Telêmaco ${ }^{34}$, que me fora dado pelo Sr. Philips, e, neste novo mundo de jardins perfumados, parecia escutar Mentor $^{35}$ em conversa nos Cam-

33 Antes de vir definitivamente para a América do Sul, Bonpland foi "jardineiro" da imperatriz Josefina, título de alta consideração, na época, uma vez que a atividade não se limitava a cuidar dos jardins, correspondendo, mais precisamente, ao de "botânico da corte".

${ }^{34}$ Personagem da mitologia grega, Telêmaco era filho de Ulisses e Penélope. pos Elíseos ${ }^{36}$, com um dos sábios de outra era. Por vezes fizemos longos passeios a cavalo, pois o vigor do Sr. Bonpland, à semelhança de sua memória, e apesar de sua idade, o fazia um cavaleiro infatigável.

"Tal como observa, com propriedade, o Sr. Humboldt, seu ilustre amigo, que o conheceu na intimidade, ele extraiu dos Andes essa vitalidade centenária, que não enfraquece nem a atividade do corpo, nem as questões do espírito. Parece que os viajantes que exploraram as altas montanhas, vizinhas do céu, são como os navegantes das regiões boreais. Ao visitar Greenwich, nos curvamos, com surpresa, perante os séculos errantes, aos que passaram sua juventude em meio aos gelos eternos dos pólos. A mesma longevidade parece reservada aos viajantes que alcançaram os picos nevados do Illimani ${ }^{37}$ e Chimborazo ${ }^{38}$ ". 39

Desde os primeiros momentos de nossa chegada, o Sr. Bonpland nos avisou da impossibilidade de visitarmos o Paraguai. Ele nos contou sobre todas as dificuldades que um de nossos compatriotas tinha passado para ir e voltar, o Sr. Demersay ${ }^{40}$, que acaba de retornar à Europa. Foi necessária a intervenção do Ministro do

${ }^{35}$ Sábio e fiel amigo de Ulisses, rei de Ítaca, personagem mitológico da obra Odisséia, de Homero.

${ }^{36}$ De acordo com a mitologia grega, os Campos Elísios era um local "sem tormentos" do reino de Hades, destinado para digno repouso dos homens de virtude após a morte. Local privilegiado, as almas ali podiam dançar, comer e se divertir dia e noite, em seus verdes e floridos campos.

${ }^{37}$ Vulcão extinto, de $6.462 \mathrm{~m}$ de altitude. É a montanha mais alta da Cordilheira Real, e marca inconfundível da paisagem urbana de La Paz, capital da Bolívia.

38 Pico mais elevado dos Andes equatoriais $(6.267 \mathrm{~m}$ de altitude), situado perto de Riobamba, cerca de $180 \mathrm{~km}$ ao sul de Quito (Equador). Até o início do século XIX, o Chimborazo era considerado o pico mais elevado da Terra. Em 1802, Alexander von Humboldt tentou escala-lo, juntamente com Aimé Bonpland e Carlos Montúfar, mas eles tiveram de abandonar o projeto a $5.875 \mathrm{~m}$, devido à rarefação do ar.

${ }^{39}$ DEMERSAY, A. Histoire physique, économique et politique du Paraguay et des établissements des Jésuites. Paris: L. Hachette et Cie., 1860. v. 1. p. 45. 
Brasil em Assunção ${ }^{41}$ para obter um passaporte do presidente Lopez $^{42}$; mas este ministro, ele próprio, também teve de sair do Paraguai. "Além disso, acrescentou, vou tentar compensá-lo desse contratempo da melhor maneira possível, partilhando as memórias que guardo desse país, e repassar as observações mais recentes, feitas pelo Sr. Demersay".

Um dos primeiros pontos que me tinham interessado a visitar o Paraguai eram as famosas Missões dos Jesuítas; eu queria ver por mim mesmo o que resta desses célebres estabelecimentos, que tiveram tantos apologistas quanto detratores.

Você pode ter uma idéia, disse o Sr. Bonpland, da construção ou da forma material dessas missões pelo que ainda subsiste na de São Borja. Esta é uma das melhor preservadas na margem esquerda do Uruguai.

Em um de nossos passeios com o Sr. Bonpland, nós visitamos os pueblos, que na primeira vez apenas tínhamos atravessado sem olhar, por assim dizer. Eis, aqui, o que nos fez observar o nosso anfitrião.

Sobre os três lados de uma praça, com cento e sessenta e dois metros de comprimento por cento e trinta de largura, aproximadamente, en-

${ }^{40}$ Alfred Demersay, médico, viajante e escritor francês, natural de Chatillon Coligne (França, 13-11-1815) e falecido em Paris (04-02-1891). Figura chave na Société de Géographie de Paris, ele foi enviado pelo governo francês para visitar a América do Sul em 1844, especialmente o Paraguai. Sua ida deu-se através do Rio Grande do Sul, tendo acompanhado a comitiva oficial que veio à província para comemorar o término da Revolução Farroupilha. Foi o próprio Imperador Dom Pedro II que recomendou a passagem do francês por São Borja, a fim de se encontrar com Bonpland. Na obra publicada por Demersay, salientam-se, por seu especial interesse à iconografia do Rio Grande do Sul: "retrato de Bonpland", "Casa de Bonpland em S. Borja", "Porta lateral e coluna de madeira da igreja de S. Borja", "Pia do colégio de S. Lourenço" e "Ruínas de São Miguel".

${ }^{41}$ Trata-se do Marquês de São Vicente, José Antonio Pimenta Bueno.

${ }^{42}$ Refere-se a Carlos Antonio López (1792-1862), pai de Francisco Solano López. "Cônsul do Paraguai", a partir de 12-3-1841, Carlos Antonio López tornou-se o primeiro presidente do vizinho país, em 13-3-1844. contram-se casas construídas apenas com o piso térreo; essas construções são de barro ${ }^{43}$ e vigas de madeira, distribuídas de maneira a formar alojamentos um tanto semelhantes ${ }^{44}$. Um teto de telhas cobre estas casas e lhes ultrapassa, compondo um peristilo ou galeria coberta em torno da praça, sustentada, de distância em distância, por pilastras quadradas, feitas de pedra rosada.

Sobre o lado norte da praça ${ }^{45}$ se encontra a igreja, que nada tem de notável por fora. O edifício compõe-se, simplesmente, de quatro paredes de pedras aparadas, encimado por um teto de telhas e uma pequena torre quadrada, expondo a cúpula no interior. O portal só difere do resto por ter sido esculpido muito artisticamente pelos índios ${ }^{46}$ sob a direção dos jesuítas e que nele não se inseriu nenhum encaixe na sua construção, à semelhança de todas as casas. Um átrio, sustentado por colunas de madeira dura, ocupa a fachada da igreja, ao qual se chega por uma escadaria quadrada, formada por alguns degraus ${ }^{47}$.

${ }^{43}$ Para que não restem dúvidas: "ces constructions sont en argile, en charpente".

${ }^{44}$ A respeito das construções desse antigo povo jesuítico, o Cônego João Pedro Gay, que foi pároco de São Borja a partir de 24 de fevereiro de 1850, registrou que "esses edifícios, que não se igualavam em segurança e elegância aos de S. Luiz, de S. Nicolau, de S. Tomé, Apóstolos, S. Xavier, etc., tiveram que desmoronar-se, não sendo consertados. O seu sistema de construção, posto que superior e mais duradouro do que os ranchos atualmente habitados (...) não permite longa duração" (GAY, 1942. Op. cit., p. 517).

45 "Sur le côté nord de la place se trouve l'église". Tratase de flagrante equívoco: a igreja da antiga Redução de São Borja foi construída na face sul da praça.

${ }^{46}$ A respeito dessa estrutura, Hemetério José Velloso da Silveira informa que "a porta principal da velha igreja é um bonito trabalho em pedra de grés, transportada de Itaqui, pois em São Borja não há pedras dessa qualidade" (SILVEIRA, 1909. Op. cit., p. 313).

${ }^{47}$ Por ocasião de sua visita a São Borja, Saint-Hilaire registrou, em fevereiro de 1820: "Ao cair da tarde, entrei na igreja, e a grandiosidade dessa construção, meio destruída, me fez experimentar um profundo sentimento de surpresa e respeito" (...). "Começarei essas anotações pela descrição da igreja de São Borja. Para nela 
À esquerda da igreja, em uma baixada, foi situado o colégio, atrás do qual havia um grande jardim, plantado com laranjeiras, limoeiros, figueiras e um grande número de plantas nativas, cercado por um muro de pedras em toda a sua extensão. Ao lado do colégio ficava o hospital, seguido por oficinas, lojas, etc. Entra-se na praça através das extremidades norte e sul. Esta praça lembra, um pouco, o aspecto de um quartel ou claustro. Irradiando-se para todos os lados, sem ordem regular, viam-se ranchos, chacras e algumas casinhas, muito propriamente construídas. As autoridades e os comerciantes mais importantes estão instalados nas antigas habitações dos índios; o comandante militar ocupa o colégio; o hospital, as lojas e as oficinas se encontram em ruínas; longe de pensar em reparos, remove-se todo o material para uso em construções novas. A própria igreja encontra-se em tal estado de deterioração que se obriga a celebrar o culto divino em uma pequena capela contígua às galerias laterais da praça.

Nós hesitamos por algum tempo até visitar o interior da antiga igreja, porque parecia em

entrar, sobem-se três degraus de pedra e passa-se por um vasto pórtico, sustentado por quatro filas de colunas de madeira, de ordem dórica, colocadas duas a duas sobre o mesmo pedestal. Esse pórtico limita com três portas pintadas e esculpidas das quais a maior corresponde à nave principal e as outras duas, a naves laterais (...). A igreja é construída de alvenaria; mas por não se acharem, até o presente, pedras de cal na região, substituíram a cal pela terra batida. Por baixo dos muros empregam reboco, composto de areia, barro e esterco de vaca que, asseguraram-me, não se desmanchou jamais pelas chuvas mais incessantes e copiosas. Não há campanário nem torre que o substitua; os sinos estão colocados no pátio do antigo convento, sob um telheiro quadrado, onde vão tocá-los; a eles se chega por uma escadinha de madeira. (...) O interior da igreja está pavimentado de ladrilhos muito irregulares; a abóboda é alta, mas de madeira, porque a falta de cal não permite construí-la de pedras. Contei cento e dezesseis passos da porta principal ao altar-mor, e quarenta e três de uma parede à outra. A nave principal é separada das laterais por oito arcadas sustentadas por colunas de madeira de ordem jônica, dispostas duas a duas sobre o mesmo pedestal. Não há coro, e os altares apenas três, um que integra a nave principal e os outros as laterais" (SAINT-HILAIRE, 2002. Op. cit., p. 329-330). vias de ruir a qualquer momento. Toda vez que soprava um vento mais violento, como o pampero, se destacavam do teto enormes vigas que, oscilando ruidosamente, sacudiam o resto do velho edifício. A forma desse edifício é um quadrado longo, sem corredores laterais nem torres; apenas na entrada do coro, acima do púlpito, se eleva a cúpula em madeira de que já falei, a qual estava decorada com pinturas muito bonitas.

Duas fileiras de colunas em madeira dura, de ordem toscana ou rústica, sustentavam a estrutura do meio, formando uma nave. Os enfeites do coro foram removidos, restando nas laterais dois altares, mas ambos nus, inspirando uma profunda melancolia.

Eu não poderia ajudar, mas ao ver o triste estado de um edifício religioso disse ao Sr. Bonpland: como é que em um país católico não se trata de conservar um monumento sagrado, que devia recordar memórias tão comoventes e excitar o zelo e a piedade de todos os fiéis?

- São os infortúnios do tempo, respondeume ele, as guerras civis e as revoluções que causaram estes desastres. Todas as outras Reduções ou Missões da margem esquerda do Uruguai estão ainda mais maltratadas do que esta ${ }^{48}$. Sobre as pessoas, aqui e ali, o que se encontram são pobres índios em cabanas ou refugiados nos edifícios dos colégios. Eles cuidaram das igrejas quando elas ainda estavam em pé, mas de todos os lados não se encontra senão a miséria, a solidão e o abandono. Poderia seguir seus traços profundos pelas devastações da guerra estrangeira, causada pela dupla invasão de hordas indisciplinadas de Artigas, liderada pelo índio Andréa Tacuari ${ }^{49}$, em 1816, e pelo general

\footnotetext{
${ }^{48}$ Segundo o autor, todas as outras reduções situadas no atual Rio Grande do Sul estavam em pior estado do que a de São Borja: "Toutes les autres Réductions ou Missions de la rive gauche de l'Uruguay sont encore plus maltraitées que celles-ci".

49 Andresito Artigas, Andrés Artigas, Andrés Guazurary ou Andrés Guacurari (1778-1825), filho adotivo de José Gervásio Artigas, prócer uruguaio. De família guarani, Andresito nasceu em Santo Tomé ou, de acordo com
} 
Rivera $^{50}$, em 1828; e os desastres mais recentes, mas não menos deploráveis, da guerra civil $^{51}$ nesta parte do Brasil, aliviada, apenas, por um tempo muito curto.

"Esta é, continuou ele, a situação atual dos sete pueblos ou Missões da margem esquerda do Uruguai, pertencentes ao Brasil e à província do Rio Grande do Sul, mas ruínas ainda menos notáveis se encontram lá do que aqui, posto que as quinze Reduções construídas entre o Uruguai e o Paraná, na parte nordeste da província de Corrientes ${ }^{52}$, desapareceram completamente ${ }^{53}$. Finalmente, oito Missões, das trinta fundadas pelos jesuítas, se encontram no Paraguai propriamente dito, e ainda subsistem. Aquelas foram respeitadas pelas guerras civis, e seus edifícios ainda estão em pé, e seu regime administrativo funciona de modo semelhante ao originalmente concebido pelos fundadores das Missões".
Esta é a região onde o viajante de quem falei ${ }^{54}$ pôde estudar esse regime, recolher informações próprias e as fornecidas pelo $\mathrm{Sr}$. Bonpland, que passou dez anos nessas Missões $^{55}$, e escreveu uma história dessas instituições, a qual se espera, ansiosamente, pela publicação. Pode-se presumir que será um tipo de profissão de fé o que o autor vai publicar.

"Falar dos jesuítas, disse ele, até mesmo os da América, é uma tarefa muito espinhosa, grande ou, pelo menos, um amontoado de suposições. E, no entanto, é preciso lembrar que a despeito de qualquer opinião que se tenha da influência, das intenções políticas, ou dos projetos secretos da famosa empresa ${ }^{56}$ na Europa, não se pode ignorar, sem injustiça, os grandes serviços prestados no Novo Mundo para a causa da humanidade. Enviados para subtrair os índios da ganância dos conquistadores, de medidas vexatórias dos governadores e do som dos veementes protestos do bispo de Chiapas $^{57}$, os jesuítas realizaram sua difícil tarefa mediante inúmeros e indizíveis obstáculos, e de perigos que puseram em suas fileiras mais de um mártir. Sua austeridade desafiou todas as acusações, todas as calúnias; e sua administração deixou, entre os indígenas, lembranças que sucumbiram sob a pressão dos que os sucederam. Criticou-se, fortemente, o regime das Missões, e eu não quero fingir que ele conviria a uma sociedade como a nossa; mas um povo jovem, de homens imprevidentes, que não levam em conta o dia-a-dia, deve ser governada por meios e aparato adequado à populações jovens. A destruição da ordem deixou um vazio enorme na América ${ }^{58}$, que os viajantes são

${ }^{54}$ Referência a Alfred Demersay.

55 Bonpland ficou preso (ou retido) no Paraguai por quase dez anos, de dezembro de 1821 ao início de 1831 .

${ }^{56}$ Companhia de Jesus é o nome oficial da Ordem dos Jesuítas.

${ }^{57}$ Alusão a Bartolomé de las Casas (1474-1566), frade dominicano, cronista, teólogo e bispo de Chiapas (atual México). Grande defensor dos índios, ele foi, provavelmente, o primeiro sacerdote ordenado na América.

${ }^{58}$ Os jesuítas foram expulsos das terras portuguesas em 1767, e em 1773 das espanholas. 
unânimes em denunciar. Sob todos os aspectos, a obra social desapareceu há longo tempo, e quase toda a obra material está prestes a desaparecer... Em poucos anos, a solidão reinará em meio a esses magníficos estabelecimentos; os índios refarão o caminho dos desertos e se espalharão pelas florestas que seus ancestrais haviam abandonado, sob a voz persuasiva de homens cuja reputação de mansidão e de caridade havia chegado até eles. Deve-se excluir deste quadro o Estado do Paraguai, cujo isolamento depois de Independência o preservou da mania quase endêmica de revoluções nas ex-colônias de Espanha, e graças a essa tranqüilidade tradicional, obtida a caro custo, conservou, intactos, os monumentos da grandeza e riqueza da ordem famosa, cujo nome haverá de permanecer associado aos mesmos, no futuro". 59

Eis, em poucas palavras, o resumo da história das Missões, tal como eu a recolhi de diferentes conversas mantidas com o Sr. Bonpland a esse respeito, e do estudo que fiz com os autores que escreveram com imparcialidade.

Estes instruídos e hábeis religiosos nem sempre se limitaram, em verdade, à persuasão e à pregação apostólica para reduzir os índios. Eles também se serviram de meios temporais, mas sabiam como usá-los com muita parcimônia e cautela. A formação de povoados jesuítas ao longo do Paraná e Uruguai também se deve, em grande parte, ao medo que a feroz tirania portuguesa inspirava aos índios. Mas sempre, e acima de tudo, a moral do cristianismo foi pregada entre essas tribos independentes, e não demorou muito para operar mudanças salutares, que acabaram com a vantagem das Missões e, mais tarde, permitiu a formação de pueblos (povoados), mesmo nos pontos mais remotos do interior.

Examinemos o regime interno das Missões, pois ele é importante para se ter um boa idéia dos proveitos que os neófitos poderiam ter com os missionários.

${ }^{59}$ DEMERSAY, A., 1860-1865. Op. cit., v. 1 (Introdução).
Tudo foi perfeitamente arranjado para que eles não sofressem nenhuma necessidade física. Colocando-se à frente dos povoados de índios convertidos, os missionários se ocupavam de assegurar a subsistência de seus neófitos, e eles os faziam trabalhar para a comunidade, suprindo a falta absoluta de previsão, que habitualmente demonstram os Americanos.

Não se pode esconder o fato de que o mais difícil na civilização de um povo selvagem é a submissão a um trabalho regular, é fazer com que se compreenda que isso é o que garante a previsão, posto que os suprimentos tornam-se indispensáveis aos que já formam uma sociedade em que a necessidade se faz sentir com o fim da vida nômade, e as pessoas se acostumam a todas as exigências da vida sedentária. É nessa circunstância importante que gasta a maior parte do tempo os que se ocupam em reunir em sociedade as nações selvagens, e temos de admitir que, geralmente, é necessário o uso do grande esforço empregado pelos jesuítas para levar os neófitos ao trabalho. ${ }^{60}$

Em pensadores profundos, que investigaram e conhecem o coração humano, os padres entenderam que para as pessoas que não temem a fadiga quando a imaginação está ocupada, era necessário que o trabalho fosse, de algum modo, uma festa ou, pelo menos, apresentar tal aspecto. Tratava-se, como se viu, do trabalho atraente sonhado por um utópico moderno ${ }^{61}$, mas,

${ }^{60}$ DENIS, F. Résumé de l'histoire de Buenos-Ayres, du Paraguay et des provinces de la Plata. Embora assim referida pelos autores, cabe informar que essa obra de Ferdinand Denis foi publicada em Paris, em 1827, pela editora Lecointe et Durey, com o nome completo de "Résumé de l'histoire de Buenos-Ayres et des provinces de la Plata, suivi du résumé de l'histoire du Chili, avec des notes".

${ }^{61}$ FOURIER - Ce n'est pas le seul emprunt que l'auteur du système phalanstérien a fait aux établissements des Missions du Paraguay (nota do autor). Tradução: "Este não é o único empréstimo que o autor do sistema falansteriano extraiu de instituições das Missões do Paraguai". Resta informar que o termo falansteriano se aplica aos seguidores ou sectários do sociólogo francês Charles Fourier (1772-1837), um dos pais do cooperativismo. 
em seguida, aplicado em uma medida justa, em todas as circunstâncias, enquanto excepcional, e, sobretudo, santificado pela religião; uma vez que a religião foi associada com estas festas da agricultura, e nesse caso daquela maneira.

Na hora marcada para ir aos campos, construía-se com ramos novos um tipo de cúpula de verdura sob a qual era colocada uma estátua da santa Virgem; a música se fazia ouvir, os cultivadores transportavam este tipo de altar pelo campo, o adornavam com flores, e se entregavam aos trabalhos ao som de instrumentos que não cessavam de tocar melodias capazes de lhes animar. Além disso, o tempo dedicado ao cultivo sempre era de curta duração, e nisso os jesuítas mostraram um perfeito conhecimento do caráter de seus neófitos.

Os produtos geralmente cultivados não ofereciam uma grande variedade, eram os mesmos que os selvagens usavam habitualmente. Eles se ocupavam, principalmente, com o milho, o mate ou chá do Paraguai, e o algodoeiro, este em locais em que o terreno lhe era favorável. Todos estes produtos agrícolas não eram entregues para cada agricultor, eram reunidos em depósitos pertencentes a cada comunidade. Cada índio recebia a mesma ração de milho, carne e mate. Esta ração era abundante; tinha sido calculada com base nas necessidades dos nativos, os quais eram capazes de suportar os jejuns mais austeros e os excessos mais perigosos.

A vestimenta era, como se deve pensar, extremamente simples, o que levou os índios, por vezes, a adotar as nossas, que estão ligadas a partir de prerrogativas que não conheciam no início, e que não tardam em conhecê-las. A roupa usada pelas pessoas consistia em um vestido branco. Os oficiais do povoado, sempre escolhidos entre os índios, eram vestidos com uniformes brilhantes, vindos da Europa.

As mulheres, alimentadas como os homens, vestiam-se à semelhança deles. Estavam quase que exclusivamente ocupadas em fiar a quantidade de algodão que lhes era entregue a cada semana, como tarefa que não podia ser dispensada, e o resto de seu tempo era empregado em trabalhos que dizem respeito ao interior da própria casa.

Foi nas Missões que se pode provar que o americano é dotado, talvez mais do que os habitantes do mundo antigo, a esta indústria que exige, ao mesmo tempo, a habilidade e a observação, e que, se em sua simples casa ele não reúne todos os utensílios que se mostram úteis, é por que ele os desdenha de usar, pois um momento roubado à tranqüilidade parece-lhe muito caro por objetos que não lhe são indispensáveis. É verdadeiramente surpreendente o número de trabalhadores hábeis criados pelos jesuítas. Além disso, seus talentos foram dedicados ao embelezamento das igrejas e colégios, e nós vimos amostras notáveis ao visitar a igreja de São Borja; mas eles jamais empregaram seus talentos para decorar o interior de suas próprias casas, seja por que não lhes teria sido autorizado, ou melhor, por estarem pouco dispostos a esse gênero de trabalho, desde que não fossem obri$\operatorname{gados}^{62}$.

Cada povo era governada por dois jesuítas. Um deles, com o título de cura, era o encarregado da administração geral, e aparecia para os neófitos somente em ocasiões importantes, como nas festas solenes, onde sempre ocupava o primeiro lugar. O outro, dito vice-cura ou vigário, era o encarregado mais diretamente das questões espirituais; estando em contato permanente com os índios, falava a sua língua, e lhes dava instrução religiosa. Depois vinham os chefes civis escolhidos entre os índios, sob os títulos de caciques, alcaides, etc.; mas não eram senão subdelegados dos jesuítas, e exerciam uma vigilância ativa sobre tudo, para ampliar o bem-estar geral dos povoados.

Todos os índios eram iguais e não podiam ter qualquer propriedade particular. Este regime previa a única transição possível do estado bárbaro, no qual os índios se encontravam, para uma civilização mais perfeita. É verdade que

${ }^{62}$ DENIS, F. Résumé de l'histoire de Buenos-Ayres, du Paraguay et des provinces de la Plata (nota do autor). 
sob esse regime os índios não tinham nenhum motivo de emulação para desenvolverem seus talentos, posto que o mais virtuoso e o mais ativo não estava nem melhor alimentado nem melhor vestido do que os outros, e eles não tinham outros prazeres. Mas este tipo de governo era o único meio adequado a hordas tão embrutecidas, tão ferozes; ele promovia o bem-estar desses índios que, como crianças, eram incapazes de governar a si mesmos. Foi uma mudança muito bem-vinda para esses selvagens, acostumados a matar uns aos outros, ou a servir aos espanhóis como escravos. Os indivíduos e os comandantes espanhóis anteriormente licenciados, contrários às leis explicitadas a este respeito, reduziam à escravidão todos os índios que caíam em suas mãos. Vêm daí as primeiras sementes de ódio contra os jesuítas. "Queixas de comandantes militares, como disse o Pe. Aguilar, em sua declaração de apoio dirigida ao rei de Espanha, devem-se a que eles gostariam de submeter os índios não apenas à Vossa Majestade, mas a todos os espanhóis, em particular, e até mesmo aos servos e escravos dos espanhóis".

Critica-se nos jesuítas a ignorância na qual eles educaram seus neófitos. É verdade que ensinaram os princípios da religião, e o que era necessário para receber os sacramentos da Igreja. Ensinaram-lhes os mandamentos de Deus, o Pai-Nosso, a Ave-Maria, o Credo dos Apóstolos e algumas orações: era um início de instrução moral o que os jesuítas, sabiamente, reduziram seus primeiros esforços. Eles não aprenderam qualquer ciência, qualquer língua estrangeira, mas eles fizeram as telas de suas vestimentas. As artes mecânicas lhes foram ensinadas pelos jesuítas enviados da Europa para esse fim. Empregaram-se os escassos lucros de uma cultura emergente para adquirir instrumentos, utensílios e armas. Índios neófitos levavam às cidades espanholas tudo o que restava de seus tecidos, tabaco, erva-mate, peles. Esses produtos eram entregues ao procurador-geral dos missionários, que lhes vendiam ou trocavam da maneira mais vantajosa possível. Fazia-se, então, uma contagem exata de tudo e, depois de extrair o tributo do pagamento dos bens, usavase o restante para comprar coisas úteis ou necessárias aos índios.

Os índios das Missões eram pessoas livres que estavam sob a proteção do rei da Espanha. Eles concordaram em pagar um tributo anual de uma piastra por cabeça. Eles foram forçados a se juntar aos exércitos espanhóis em tempo de guerra, de se armarem à sua própria custa, e de trabalhar nas fortificações. Eles prestaram grandes serviços à Espanha, na guerra contra os portugueses. A despeito de convenções consagradas, não se teve nenhum escrúpulo ao tratar estes cristãos como uma tropa de gado. Em 1757, parte do território das Missões foi cedida pela Espanha à corte de Portugal. Argumentou-se que os jesuítas recusaram-se a submeter a esta entrega, ou de se deixar transferir de um lado para outro sem o seu consentimento. Os índios, na verdade, pegaram em armas, mas eles foram facilmente derrotados, e com grande carnificina, pelas tropas européias enviadas para lhes subjugar $^{63}$. A rapidez dessa derrota prova que não havia união entre eles, nem chefes. Em 1767, seus padres foram expulsos da América por ordem do rei, e os infelizes neófitos submetidos a outros habitantes nativos daquele país.

Desde a expulsão dos jesuítas, os frades que foram encarregados de cuidar de seus povoados não alimentaram nem vestiram os índios como antes, e os fatigaram de tanto trabalho. Os comerciantes e os comandantes militares puderam recomeçar os seus abusos. Finalmente, um relatório ministerial sem precedentes, dirigido ao Rei de Espanha por um inimigo dos jesuítas, disse que "a população dos Trinta Povos Guaranis, estabelecidos pelos religiosos, ascendia, em 1774, a 82.066 indivíduos, e que, durante a expulsão dos jesuítas era de, pelo menos, cem mil; que ela foi reduzida, em vinte

\footnotetext{
${ }^{63}$ Referência à Guerra Guaranítica, travada entre os índios guaranis e as tropas espanholas e portuguesas, que culminou na Batalha de Caiboaté (fevereiro de 1756), em que veio a falecer Sepé Tiarajú.
} 
anos, em 42.250 almas, ou seja, em mais da metade; os portugueses, antes contidos, invadiram sete aldeias, e para deter a invasão desses estrangeiros teve-se que restaurar o excelente regulamento militar dos jesuítas." Estes são fatos que falam por si. Vimos, anteriormente, o estado a que acabaram reduzidas vinte e duas, das trinta Missões. No entanto, vamos nos antecipar e dizer que nem todos os índios que as compunham retornaram às florestas, retomando a vida selvagem de seus antepassados; um grande número deles, deixados a si mesmos, continuou a se civilizar; eles ainda desfrutam de algum bem-estar e muitos se vestem como espanhóis; alguns adquiriram propriedades e se mostram cidadãos dedicados, bons pais de família e, sobretudo, cristãos fervorosos; o que se pode concluir desses fatos isolados, senão que os brotos da árvore magnífica que uma política cega pôs a perder, mas não conseguiu arrancar inteiramente?

Oito pueblos estabelecidos no Paraguai ainda permanecem com sua organização original, exceto que os magistrados atualmente encarregados pela administração são laicos. Mas o trabalho em conjunto, a posse comum das terras e a distribuição per capita dos produtos pela população ainda ocorrem segundo as normas estabelecidas pelos jesuítas ${ }^{64}$.

Ao falar do Paraguai, o Sr. Bonpland nos falou, necessariamente, do famoso Dr. Francia, mas fê-lo com tanto tato e moderação, que só aumentou, ainda mais, a veneração que eu tinha para com nosso sábio compatriota. Apesar

${ }^{64}$ Desde 7 de Outubro de 1848, esse estado de coisas cessou. Um decreto do presidente Lopez, publicado nesta data, declarou os índios de todas as aldeias cidadãos da República, inserindo-os no direito comum, suprimindo sua jurisdição particular, estabelecendo novas autoridades, etc. "Eu não sei, disse o Sr. Demersay depois de citar esse fato, as consequiências de tal ação tomada pelo Presidente Lopez; e a experiência dirá, em breve, se os índios liberados dos trabalhos da comunidade são dignos da liberdade que lhes foi outorgada com frases de um liberalismo sonoro, do qual tenho razões para duvidar" (nota do autor). de suas justas queixas contra o ditador, e as fez com justiça, depois de haver imposto um jugo de ferro sobre o Paraguai por vários anos, ele foi capaz de disseminar pelo país o gosto pelo trabalho, pelas artes e a boa ordem, acrescentando que o governo havia suavizado nos últimos anos de sua vida, e as boas intenções transpareciam em seu despotismo, em vários momentos.

Quinze dias depois da nossa chegada a São Borja, teve-se que pensar no retorno. Decidimos aproveitar uma pequena embarcação que estava em Itapua $^{65}$, a poucos dias daqui, para descer o Paraná. O Sr. Bonpland quis acompanhar-nos até o lugar de nosso embarque, apesar de nossos protestos e nosso empenho em lhe deter. "O quê!, disse ele, vocês querem me impedir de prolongar o prazer que tão raramente tenho, de falar francês com franceses? Além disso, a região que vocês vão percorrer até Itapua não é muito segura para estrangeiros neste momento; além disso, eu a conheço perfeitamente, nada tenho a temer, e minha presença vos será útil". Foi impossível demove-lo.

Percorremos rapidamente a parte da província de Corrientes que se estende entre São Borja e o rio Paraná, frente à cidade de Itapua, em um pequeno porto, onde encontramos o navio em questão. Era uma pequena escuna de Buenos

${ }^{65} \mathrm{O}$ nome Itapúa é muito antigo na região do rio Paraná, tendo sido inicialmente utilizado pelo padre jesuíta Roque González de Santa Cruz para designar a Redução de Nuestra Señora de la Anunciación de Itapúa, fundada a 25 de março de 1615, no sítio atualmente ocupado pela cidade argentina de Posadas, capital da província de Misiones. Cabe salientar que essa redução teve vida efêmera, tendo sido transladada para o outro lado do rio em 1621, onde hoje se encontra a cidade de Encarnación, frente a Posadas. Ao referir que os viajantes foram até o "rio Paraná, frente à "cidade de Itapúa", o autor indica que a "pequena escuna" para Buenos Aires foi tomada em um "pequeno embarcadouro" na margem esquerda do rio Paraná. Este fato é plausível, posto que Bonpland, que teria acompanhado os viajantes (segundo o autor), não poderia passar para o lado paraguaio, onde ficara retido por cerca de dez anos. Resta informar que Itapúa, atualmente, é o nome do departamento da República do Paraguai, cuja capital é a cidade de Encarnación. 
Aires, que não criou nenhuma dificuldade para levar-nos como passageiros, em vista de nossos passaportes.

Finalmente, chegou o momento de nos separarmos do bom velho. Ele nos garantiu que iria juntar-se a nós na França, por que ele disse que queria retornar antes de morrer, não para terminar seus dias lá, mas para rever lugares caros à sua memória. Nós tivemos cuidado de não destruir essa esperança, mas consideramola pouco fundamentada; e, na verdade, nunca o Sr. Bonpland a realizou, embora ele conservasse tal ilusão até os últimos dias de sua vida. Alguns meses antes de sua morte, ele ainda escreveu a um de seus amigos em Paris:

“O vívido desejo de retornar à França está profundamente gravado em meu coração, e os diversos trabalhos de que te falei continuam em caminho certo, nada vai me deter mais por aqui, e irei rever a Malmaison. Mas essa viagem será curta; vou oferecer ao governo minhas coleções botânicas e mineralógicas para serem depositadas no Museu, e voltarei ao meio de minhas plantações no Uruguai" $"$.

O Sr. Bonpland tinha oitenta e quatro anos quando escreveu esta carta; foi no final de 1857. Ele morreu, ou antes, apagou suavemente em sua fazenda em Santa Anna, perto do Uruguai, em 12 de maio de $1858 .{ }^{67}$

Nossa viagem pelo rio Paraná foi feito com uma rapidez maravilhosa, em comparação com tempo que levamos remontando o rio Uruguai, mas desta vez nós descíamos o rio, onde a corrente é rápida e a navegação não é interrompida por qualquer obstáculo. Cinco dias após o embarque, chegamos a Buenos Aires.

\footnotetext{
${ }^{66}$ Extraído de uma carta endereçada ao Sr. Demersay (nota do autor).

${ }^{67}$ Em verdade, Aimé Bonpland faleceu a 04 de maio de 1858 .
}

Infelizmente, durante a nossa ausência a questão do Prata não tinha avançado um passo; ela havia retrocedido, inclusive, e a guerra civil continuava ainda mais ardente às margens do grande rio da Prata. A energia dos agentes da intervenção permaneceu impotente diante da obstinação do general Rosas, que sabia que o Conselho de Ministros da França estava pouco disposto a entrar em luta com ele. Quando apresentamos os nossos passaportes para viajar ao Chile, através dos pampas, eles foram recusados e deram-nos a entender que seria sensato deixarmos Buenos Aires.

\section{BIBLIOGRAFIA CITADA}

B***, A. de. Mes voyages avec le Docteur Philips dans les Républiques de La Plata (Buenos-Ayres, Montevideo La Banda Oriental etc.). Tours: Alfred Mame et fils, éditeurs, 1876. 192 p.

BARRETO, A. Bibliografia sul-riograndense. Rio de Janeiro: Conselho Federal de Cultura, 1976. v. 2. p. 737-1.556.

BELL, S. A life in Shadow. Aimé Bonpland in Southern South America, 1817-1858. Stanford, California: Stanford University Press, 2010. 320 p.

DEMERSAY, A. Histoire physique économique et politique du Paraguay et des établissements des Jésuites. Paris: Hachette \& Cie., 1860. v. 1. p. 45

FORTES, A.B.; WAGNER, J.B.S. História administrativa, judiciária e eclesiástica do Rio Grande do Sul. Porto Alegre: Editora Globo, 1963. 497 p.

GAY, J.P. História da República Jesuítica do Paraguai. Rio de Janeiro: Imprensa Nacional, 1942. $644 \mathrm{p}$.

SAINT-HILAIRE, A. de. Viagem ao Rio Grande do Sul. Brasília: Senado Federal, 2002. 578 p.

SILVEIRA, H.J.V. da. As Missões Orientaes e seus antigos dominios. Porto Alegre: Livraria Universal de Carlos Echenique, 1909. 702 p. 